\title{
A Study on the Loss Compensation Estimation of Marine Living Resources Resulting from the Land Reclamation in China
}

\author{
Xiuhua Yan ${ }^{1, a}$, Rongshuo Cai ${ }^{1, b}$ and Yashu Bai ${ }^{1, c}$ \\ ${ }^{1}$ Key Laboratory of Global Change and Marine-Atmospheric Chemistry of State Oceanic \\ Administration (SOA), Third Institute of Oceanography, SOA, Xiamen, 361005, China \\ ayanxiuhua@tio.org.cn, bcairongshuo@tio.org.cn, 'baiyashu@tio.org.cn
}

\begin{abstract}
Keywords: compensation estimation, marine living resources, land reclamation.
Abstract. In this article, the loss of marine living resources resulting from the land reclamation as part of the sea-development plan for the regional construction of Niutou Bay, Changle, Fujian Province (including monetary value) was studied, based on the data of this area and the current estimation method for loss compensation of living marine resources. The results revealed that many uncertain factors were observed in the current estimation method. These factors include the estimation of the loss of benthos resources, the market prices of biological resources, the determination of the loss rate of biological resources, and the effect area of the suspended sediment from constructions, etc. Therefore, a method aiming at improving the accuracy of current estimation method based on the investigation of biological resources, the determination of the loss type and the prediction accuracy for the effect area of pollutants is presented. This paper could serves as a good reference for the optimization of current estimation method for loss compensation of marine ecosystem in the future.
\end{abstract}

\section{Introduction}

In order to alleviate the shortage of land, large-scale land reclamation projects have been conducted in the coastal areas of China since 2000. In the period of the "Eleventh Five-year Plan", up to 7 million $\mathrm{km}^{2}$ of extra land was generated for industrial and construction usages ${ }^{[1]}$. Nevertheless, the land reclamation had a severe negative effect on the marine ecology in these areas. Therefore, the compensation approaches for marine ecological resources have been developed in China. Currently, the fund for ecological recovery (executed by the authority, including proliferation, release and the construction of protection zones) compensation comes from relevant users. For this reason, effective and accurate approaches for the evaluation of ecological recovery cost are highly demanded so that the interest of users is maximized while the recovery projects can be achieved. Indeed, these approaches are the basis of marine ecological compensation and sustainable usage of marine resources.

In order to calculate the marine ecological compensation, the ecological damage by the land reclamation needs to be evaluated. Previous studies focused on evaluation of the effects of land reclamation on the service functions (such as supply, regulating, cultural supports) of the marine eco-system using appropriate approaches, as well as the monetary value of the loss ${ }^{[2-4]}$. Nevertheless, current evaluation approaches are immature and inaccurate, thus not ideal for practical applications. Therefore, compensation for marine living resources is considered in the land reclamation projects. For this reason, effective and accurate evaluation approaches for the marine living resources loss caused by land reclamation are essential for sustainable use of marine resources. However, current approaches are highly random and the results are relatively unreliable, resulting in limitations of sustainable use of marine resources. In this article, the compensation assessments of marine living resources resulting from the land reclamation as part of the sea-development plan for the regional construction of Niutou Bay, Changle, Fujian Province (known as 'the case' in the following sections) was studied based on the data of this area and the current estimation method ${ }^{[5]}$. The factors affecting the accuracy and reliability of the evaluation approaches were discussed and suggestions to improve current approaches were provided. 


\section{Evaluation approaches and case study}

\section{Current evaluation approaches}

Currently, the compensation assessments of marine living resources are based on the "Technical Regulation for impact assessment of construction projects on marine living resources" (SC/T9110-2007, known as 'the Regulation' in the following sections) ${ }^{[6]}$. According to this regulation, the loss of marine living resources is categorized into two groups, the area occupied for construction projects and the area affected by contaminants.

i) Calculation of living resource losses

Loss from the area occupied for construction projects:

Loss of living resources = living resource density $\mathrm{x}$ area/volume occupied;

Loss from the area affected by contaminants consists of one-time loss and continuous loss:

One-time loss of living resources $=$ living resource density in the affected area $\mathrm{x}$ affected area $\mathrm{x}$ loss rate;

Herein, the major contaminant from constructions is the suspended sediment. The Regulation provides the living resources loss rates corresponding to different levels of suspended sediment. Additionally, continuous loss should also be included if the contaminant is not removed in 15 days.

Continuous loss of living resources $=$ one-time loss of living resources $\mathrm{x}$ affecting period (actual days/15)

ii) The monetary value of marine living resources loss

According to the Regulation, the monetary value of living resources can be assessed by the following formula:

Loss = quantity $\mathrm{x}$ market price $\mathrm{x}$ compensation period $\mathrm{x}$ survival percentage of roe;

Herein, the compensation period is no less than 20 years if the damage is irreversible. For one-time losses, the compensation should be 3 times the loss caused; for continuous losses, the compensation should be discussed based on the actual affecting period.

\section{Current evaluation approaches}

The target is a sea area located in the Niutou Bay, Changle, Fujian Province (see Fig. 1). The average depth is $18-20 \mathrm{~m}$, the 10 -meter depth contour is $200-2000 \mathrm{~m}$ away from the coastal line and the occupied area is $474.5 \mathrm{~km}^{2}$.

Assessment results According to the Regulation and observation data of 2013, we evaluated the losses (including one-time and irreversible losses) caused by construction and contaminants respectively, including the quantity of resources loss and their monetary values. The results are shown in Table 1 and Table 2.

According to Table 2, overall loss of the case is estimated to be 125.3 million RMB. The loss of benthos is the major part $(94.7 \%)$ of the ecological compensation, which can be attributed to the destructive losses of benthos caused by land reclamation. Besides that, the losses of fish larvae and other larvae due to land reclamation are also significant, as well as the loss of various living resources due to suspended sediment. 


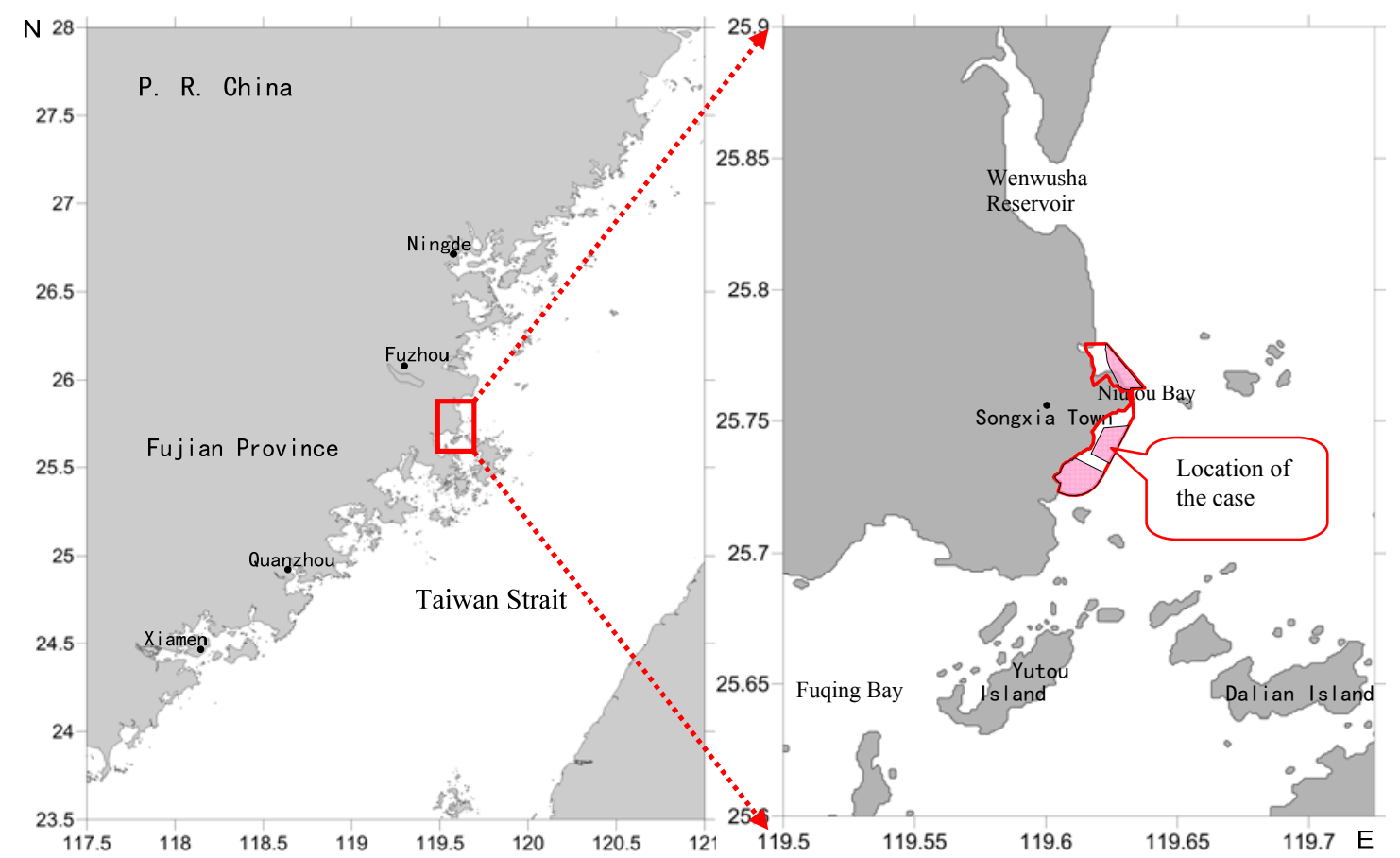

Fig. 1. The location of targeted area in Niutou Bay

Table 1: The average losses of two kinds of marine living resources affected by the land reclamation

\begin{tabular}{|c|c|c|c|c|c|}
\hline Category & Biological species & Density & Affected area $\left(\mathrm{km}^{2}\right)$ & $\begin{array}{l}\text { Loss } \\
\text { rate }\end{array}$ & Quantity lost \\
\hline \multirow{10}{*}{$\begin{array}{l}\text { Constructio } \\
n\end{array}$} & Phytoplankton & $29955 / \mathrm{m}^{3}$ & \multirow[t]{8}{*}{474.5} & \multirow{10}{*}{$\begin{array}{l}100 \\
\%\end{array}$} & $8.0 \times 10^{11}$ \\
\hline & Zooplankton & $43.8 \mathrm{mg} / \mathrm{m}^{3}$ & & & $1.16 \mathrm{t}$ \\
\hline & Roe & $157.5 / 1000 \mathrm{~m}^{3}$ & & & $4.2 \times 10^{6}$ \\
\hline & Larvae & $67 / 1000 \mathrm{~m}^{3}$ & & & $1.8 \times 10^{6}$ \\
\hline & Fish larvae & $1.67 \times 10^{4} / \mathrm{km}^{2}$ & & & 79242 \\
\hline & Shrimp larvae & $1.23 \times 10^{4} / \mathrm{km}^{2}$ & & & 58364 \\
\hline & Crab larvae & $0.16 \times 10^{4} / \mathrm{km}^{2}$ & & & 7592 \\
\hline & Cephalopod larvae & $0.08 \times 10^{4} / \mathrm{km}^{2}$ & & & 3796 \\
\hline & Benthos in the sub-tidal zone & $24.25 \mathrm{~g} / \mathrm{m}^{2}$ & 399.5 & & $96.88 \mathrm{t}$ \\
\hline & Benthos in the inter-tidal zone & $661.58 \mathrm{~g} / \mathrm{m}^{2}$ & 75.0 & & $496.19 \mathrm{t}$ \\
\hline \multirow[t]{16}{*}{ Contaminant } & \multirow[t]{2}{*}{ Phytoplankton } & \multirow[t]{2}{*}{$29955 / \mathrm{m}^{3}$} & $5.86(1<\mathrm{Bi} \leq 9)$ & $10 \%$ & $9.83 \times 10^{10}$ \\
\hline & & & 0.71（Bi>9） & $50 \%$ & $5.96 \times 10^{10}$ \\
\hline & \multirow[t]{2}{*}{ Zooplankton } & \multirow[t]{2}{*}{$43.8 \mathrm{mg} / \mathrm{m}^{3}$} & $5.86(1<\mathrm{Bi} \leq 9)$ & $10 \%$ & $0.14 \mathrm{t}$ \\
\hline & & & 0.71（Bi>9） & $50 \%$ & $0.087 \mathrm{t}$ \\
\hline & \multirow[t]{2}{*}{ Roe } & \multirow[t]{2}{*}{$157.5 / 1000 \mathrm{~m}^{3}$} & $5.86(1<\mathrm{Bi} \leq 9)$ & $10 \%$ & $5.17 \times 10^{5}$ \\
\hline & & & $0.71(\mathrm{Bi}>9)$ & $50 \%$ & $3.13 \times 10^{5}$ \\
\hline & \multirow[t]{2}{*}{ Larvae } & \multirow[t]{2}{*}{$67 / 1000 \mathrm{~m}^{3}$} & $5.86(1<\mathrm{Bi} \leq 9)$ & $10 \%$ & $2.20 \times 10^{5}$ \\
\hline & & & $0.71(\mathrm{Bi}>9)$ & $50 \%$ & $1.33 \times 10^{5}$ \\
\hline & \multirow[t]{2}{*}{ Fish larvae } & \multirow[t]{2}{*}{$1.67 \times 10^{4} / \mathrm{km}^{2}$} & $5.86(1<\mathrm{Bi} \leq 9)$ & $10 \%$ & 9787 \\
\hline & & & $0.71(\mathrm{Bi}>9)$ & $50 \%$ & 5929 \\
\hline & \multirow[t]{2}{*}{ Shrimp larvae } & \multirow[t]{2}{*}{$1.23 \times 10^{4} / \mathrm{km}^{2}$} & $5.86(1<\mathrm{Bi} \leq 9)$ & $10 \%$ & 7208 \\
\hline & & & $0.71(\mathrm{Bi}>9)$ & $50 \%$ & 4367 \\
\hline & \multirow[t]{2}{*}{ Crab larvae } & \multirow[t]{2}{*}{$0.16 \times 10^{4} / \mathrm{km}^{2}$} & $5.86(1<\mathrm{Bi} \leq 9)$ & $10 \%$ & 938 \\
\hline & & & $0.71 \quad(\mathrm{Bi}>9)$ & $50 \%$ & 568 \\
\hline & \multirow[t]{2}{*}{ Cephalopod larvae } & \multirow[t]{2}{*}{$0.08 \times 10^{4} / \mathrm{km}^{2}$} & $5.86(1<\mathrm{Bi} \leq 9)$ & $10 \%$ & 469 \\
\hline & & & $0.71 （ \mathrm{Bi}>9)$ & $50 \%$ & 284 \\
\hline
\end{tabular}

p.s.: the average depth was $5.6 \mathrm{~m}$; $\mathrm{Bi}$ is the times of contaminant concentration over the value suggested by authority 
Table 2: The monetary value of marine living resources loss

\begin{tabular}{|c|c|c|c|c|c|c|c|c|}
\hline $\begin{array}{l}\text { Biological } \\
\text { species }\end{array}$ & Category & Quantity & $\begin{array}{l}\text { Market } \\
\text { price }\end{array}$ & $\begin{array}{l}\text { Survival } \\
\text { percentage }\end{array}$ & $\begin{array}{l}\text { Mature } \\
\text { mass } \\
(\mathrm{kg} / \text { one })\end{array}$ & Period & $\begin{array}{l}\text { Compensation } \\
\text { (RMB) }\end{array}$ & Percentage \\
\hline \multirow[t]{2}{*}{ Zooplankton } & Land reclamation & $0.12 \mathrm{t}$ & $5 \mathrm{RMB} / \mathrm{kg}$ & - & - & 20 & 12000 & 0.010 \\
\hline & Suspended sediment & $0.02 \mathrm{t}$ & $5 \mathrm{RMB} / \mathrm{kg}$ & - & - & 3 & 300 & 0.000 \\
\hline \multirow[t]{2}{*}{ Roe } & Land reclamation & $4.2 \times 10^{6}$ & $1 \mathrm{RMB} /$ one & 0.01 & - & 20 & 84000 & 0.671 \\
\hline & Suspended sediment & $8.3 \times 10^{5}$ & $1 \mathrm{RMB} /$ one & 0.01 & - & 3 & 25000 & 0.020 \\
\hline \multirow[t]{2}{*}{ Larvae } & Land reclamation & $1.8 \times 10^{6}$ & $1 \mathrm{RMB} /$ one & 0.05 & - & 20 & 1.8 million & 1.437 \\
\hline & Suspended sediment & $3.53 \times 10^{5}$ & $1 \mathrm{RMB} /$ one & 0.05 & - & 3 & 53000 & 0.042 \\
\hline \multirow[t]{2}{*}{ Fish larvae } & Land reclamation & 79242 & $20 \mathrm{RMB} / \mathrm{kg}$ & 1 & 0.1 & 20 & 317 million & 2.531 \\
\hline & Suspended sediment & 15716 & $20 \mathrm{RMB} / \mathrm{kg}$ & 1 & 0.1 & 3 & 94000 & 0.075 \\
\hline \multirow[t]{2}{*}{ Shrimp larvae } & Land reclamation & 58364 & $20 \mathrm{RMB} / \mathrm{kg}$ & 1 & 0.0075 & 20 & 175000 & 0.140 \\
\hline & Suspended sediment & 11575 & $20 \mathrm{RMB} / \mathrm{kg}$ & 1 & 0.0075 & 3 & 5000 & 0.004 \\
\hline \multirow[t]{2}{*}{ Crab larvae } & Land reclamation & 7592 & $20 \mathrm{RMB} / \mathrm{kg}$ & 1 & 0.1 & 20 & 304000 & 0.243 \\
\hline & Suspended sediment & 1506 & $20 \mathrm{RMB} / \mathrm{kg}$ & 1 & 0.1 & 3 & 9000 & 0.007 \\
\hline \multirow[t]{2}{*}{ Other larvae } & Land reclamation & 3796 & $20 \mathrm{RMB} / \mathrm{kg}$ & 1 & 0.1 & 20 & 152000 & 0.121 \\
\hline & Suspended sediment & 753 & $20 \mathrm{RMB} / \mathrm{kg}$ & 1 & 0.1 & 3 & 5000 & 0.004 \\
\hline Benthos & Land reclamation & $593.1 \mathrm{t}$ & $10 \mathrm{RMB} / \mathrm{kg}$ & - & - & 20 & 118.62 million & 94.696 \\
\hline
\end{tabular}

Analysis of problems in the assessments The calculation factors in the current approaches include: the density of living resources, area occupied for construction purpose, market price of living resources, compensation period, etc. As the data and parameter values used are not absolute objective, the assessment of compensation could be completely different from the actual case. As a result, the ecological compensation may be ineffective and inaccurate. Based on the assessment of the case in this project, it can be concluded that factors affecting the accuracy of assessments include:

i) Assessment of the loss caused by benthos. The percent of the loss caused by benthos in the overall loss can be up to $80 \%$ and accurate assessment of this part plays a key role in the accuracy of compensation determination. The benthos density and the areas of intertidal and sub-tidal zones are the determining factors in the assessment. Herein, the value of benthos density is determined based on current data collection approaches. Nevertheless, the Regulation does not provide a detailed guidance on the use of different data collection approaches and researchers are supposed to select an approach based on personal understanding. This could lead to a huge difference in the final results. In addition, the determination of areas of intertidal and sub-tidal zones is also a key factor affecting the compensation assessments.

ii) Market price of marine living resources. In most cases, it is a big challenge to evaluate the monetary value of various living resources as the market price varies significantly with time and districts.

iii) The incremental range of suspended sediments concentration. The incremental range of contaminants such as the suspended sediments in the marine zone is a key factor in the assessments of marine living resources loss. The diffusion range of contaminants is usually obtained by numerical simulations, whose results are highly dependent on the mode used.

iv) The loss rate of marine living resources. The Regulation serves as a reference for the determination of survival rate of larvae, compensation period and incremental ranges of sediments. However, the loss rate varies significantly in different areas and the recommended values may not be effective in certain cases. 
v) The compensation mode of marine living resources loss. Generally, the compensation mode of marine living resources is determined based on several factors, including roe, fish larvae, biological larvae and benthos. In this study, the loss of phytoplankton and zooplankton is included, while the Regulation does not provide any suggestions on this part due to the variation in the ecology and food chain of different areas.

In addition, mature creatures (excluding the benthos) were not considered in the loss assessment due to the high mobility and self-protection capability of these creatures. Nevertheless, the loss of mature creatures should be included in some projects such as submarine blasting.

\section{POTENTIAL IMPROVEMENTS ON ASSESSMENT APPROACHES}

In this section, several suggestions are provided to improve current assessment approaches. The first suggestion is to establish an accurate and viable method to determine the density of biological resources. Indeed, the density of biological resources is a key factor for the evaluation of biological conditions in the marine area affected by constructions and contaminants. The effectiveness of this parameter is dependent on the collection site and size of data. The collection site of data should be selected based on the location, the extent of reclamation and submarine topography of the construction area, as well as the erosion and hydro power conditions; the size of data should be maximized by repeating the data collection process so that the average value obtained is systematic. The second suggestion is to establish an accurate and viable method to determine the compensation species of marine living resources. More specifically, the compensation species should be determined based on the actual case and the compensation shall be comprehensive. The third suggestion is to effectively determine the market price of the living resources. The price of each species should be determined based on the economic species and dominant species in this area, as well as the price in the local market. Furthermore, as the compensation period for irreversible damages can be up to 20 years, the price evaluation should also consider the effect of inflation. The fourth suggestion is to effectively determine the area affected by the suspended sediments. This can be achieved by well-established numerical simulation approaches.

In summary, the ecological compensation is a global challenge in the past decades. To achieve effective assessment of marine living resources loss, the methodologies and approaches shall be optimized. More importantly, laws and regulations should be developed to establish compulsory compensation system and clearly define the responsibility of relevant personnel so that human factors can be minimized. Finally, advanced ecological investigation and analysis approaches should be promoted.

\section{CONCLUSIONS}

i) Current approaches for the compensation assessment of marine living resources exhibit considerable randomness. This can be attributed to the human factors in the parameter selection and data collection processes. A slight difference in the parameter value may lead to a huge difference in the final results.

ii) The percent of the loss caused by benthos in the overall loss can be up to $80 \%$ and accurate assessment of this part plays a key role in the accuracy of compensation determination. Other factors include the density of living resources, market price of living resources, compensation species, etc.

The effective compensation assessment of marine living resources starts from investigations of the density of these resources, including the data collection sites, the methodology to determine the final value, compensation species, market price and numerical simulation results of contaminant caused by the construction projects. Besides that, laws and regulations should be developed to establish compulsory compensation system and clearly define the responsibility of relevant personnel so that human factors can be minimized. 


\section{References}

[1] Ministry of Agriculture of the People's Republic of China. Technical Regulation for impact assessment of construction projects on marine living resources (SC/T9110-2007)(in Chinese).

[2] Anning Suo, Minghui Zhang \& Yonghai Yu. 2012. Loss appraisal on the value of marine ecosystem services of the sea reclamation project for Caofeidian, Marine Sciences, 36(3), pp.108-114. (in Chinese).

[3] Jianjun Wang \& Qianming Shang. 2011. The injured coastline, outlook weekly, 38, pp. 22-24.

[4] Jing Wang, Min Xu \& Yimin Zhang. 2009. Coastal Wetland Ecological Service Value Loss Appraisal of Reclamation - Take the Coastal Wetland Reclamation of Haimen for Example, Journal of Nanjing Normal University (Natural Science Edition), 32(4), pp.134-138. (in Chinese).

[5] Xuan Wang \& Weiqi Chen. 2009. Negative Ecological Impacts Caused by Sea Reclamation and Selection of Economic Evaluation Approaches, Ecological Economy, 5, pp.48-51. (in Chinese).

[6] XiuhuaYan,Rongshuo Cai \& Yashu Bai. 2014. Special Issue on marine environmental impact assessment about the regional construction of Niutouwan, Songxia Bay, Fuzhou Port. Xiamen: Third Institute of Oceanography, SOA, China. (in Chinese). 